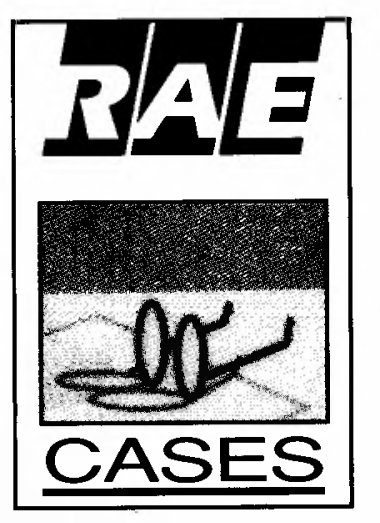

\title{
VENCENDO A CRISE: MUDANÇA ORGANIZACIONAL NA RHODIA FARMA
}

\section{Um estudo de caso sobre a superação de uma crise organizacional e a implementação de mudanças no estilo gerencial analisado sob a perspectiva cultural.}

\section{A case study on organizational crisis and implementation of changes in the management style by means of the culture metaphor analysis.}

\section{PALAVRAS-CHAVE:}

Mudança organizacional, cultura organizacional, mudança planejada, crise organizacional.

\section{KEY WORDS:}

Organizational change, organizational culture, planned change, organizationa/crisis.
* Engenheiro Químico pela UNICAMP, Mestre e Doutorando em Administracão de Empresas na EAESP/FGV.

* Cientista Social pela USP, Doutoranda em Administração e Professora do Departamento de Administração Geral e Recursos Humanos da EAESP/FGV.

***Engenheiro Químico pelo Instituto Mauá de Tecnologia, com Especialização em Administracão da Produção pela EAESP/FGV e Gerente de Qualidade na Rhodia Farma.
A década de 80 talvez represente para as organizações o que o Cretáceo representou para os dinossauros. Consumidores mais exigentes, novos competidores, redução forçada do ciclo de vida dos produtos, novo perfil da força de trabalho e muitos outros fatores vieram atormentar a vida já não tão tranqüila dos dinossauros organizacionais. Charles Handy ${ }^{1}$, conhecido autor inglês, considera as mudanças que estão ocorrendo diferentes das do passado, quando um confortável padrão de continuidade predominava. As mudanças atuais são descontínuas, exigindo uma postura mental diferente, antidogmática.

No Brasil, que enfrenta seu próprio Cretáceo desde pelo menos a década de 70, a instabilidade econômica, a falta de uma política industrial consistente, enfim, a inexistência de condições estruturais adequadas criaram um ambiente excepcionalmente complexo para os administradores de empresas. 
É nesse contexto que surge o interesse por melhor compreender os processos de mudança por que têm passado muitas organizações no Brasil. $O$ tema mudança organizacional, aliás, tem se tornado obrigatório para executivos, consultores e pesquisadores. Através desse estudo de caso pretende-se: avançar na compreensão dos fatores que catalisam o processo de mudança; identificar os elementos que podem determinar seu sucesso; discutir a possibilidade de planejar ou controlar um processo dessa natureza; compreender melhor como interagem estratégia, estrutura e cultura durante o processo.

O conceito fundamental que permeia o trabalho é o da interação entre conceitos teóricos e experiência prática ${ }^{2}$. A primeira parte corresponde a uma introdução teórica ao tema mudança organizacional. Além de conceitos de mudança, serão tratadas algumas abordagens de cultura organizacional e mudança cultural. O objetivo não é aprofundar uma discussão teórica, mas apenas fornecer um referencial para a leitura do caso prático.

A segunda parte é a narrativa dos eventos que culminaram com o colapso industrial de 1991 e o processo de mudança que se seguiu, reconstituído a partir de entrevistas com representantes de diferentes níveis hierárquicos e áreas dentro da organização. Como ilustração, são utilizados gráficos significativos da evolução de alguns parâmetros de performance e pequenas narrativas de eventos ou trabalhos relevantes do processo.

A terceira e última parte consta de uma síntese comentada das mudanças ocorridas. É também realizada uma discussão sobre a natureza e profundidade das mudanças em relação à organização do trabalho ${ }^{3}$.

Finalmente, cabe explicar por que explorar mais um caso de sucesso empresarial. São duas as razões principais: primeiro, simplesmente entender o processo de mudança e a configuração de fatores que potencializou a superação da crise e o atendimento de patamares superiores de performan$c e$; segundo, explorar criticamente alguns limites e perspectivas dos avanços alcançados ${ }^{4}$.

\section{A TEORIA DA PRÁTICA}

\section{Definindo mudança organizacional}

Apesar de muito distante de qualquer preocupação com as organizações, esta frase de Camões é quase uma definição de mudança organi-

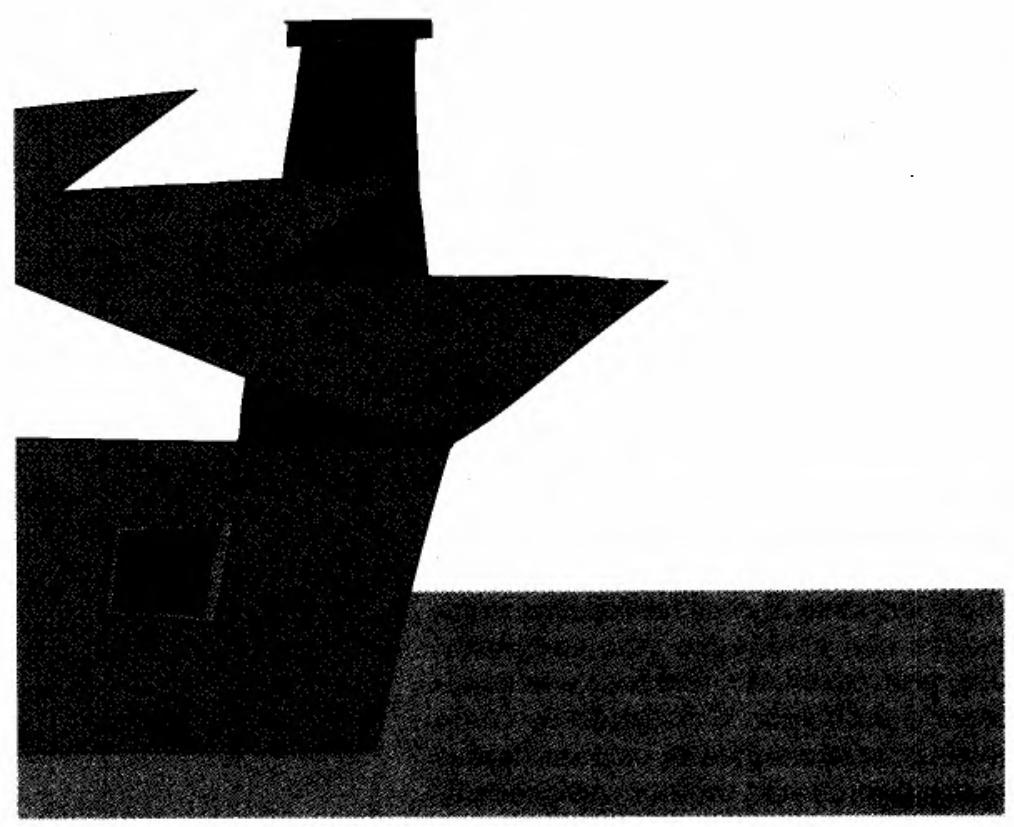

1. HANDY, C. The age of unreason. Boston: Harvard Business School Press, 1990.

2. Alexandre Koyré definiu a inovação trazida pela ciēncia moderna em termos de experimentacāo. Para ele, a ciência moderna está baseada na descoberta de uma nova e específica forma de comunicação com a natureza. Experimentação não significa meramente a observação dos fatos como eles ocorrem, nem a mera pesquisa por conexōes empíricas entre fenômenos, mas pressupõe uma interação sistemática entre conceitos teóricos e observação.

3. Embora os autores tenham optado por uma visão pan orâmica e generalista e privilegiado a abordagem via metáfora da cultura, nāo há dúvidas de que outros pontos de vista poderiam ser adotados. Da mesma forma, muitos outros aspectos poderiam ser estudados em profundidade.

4.0s processos de mudança abrem perspectivas nāo conhecidas e não previstas anteriormente, trazendo à tona novas questões e problemas para as organizações. Cabe a teóricos e práticos debruçar sobre esses processos e realizar uma reflexāo crítica, capaz de fazê-los avançar, superando continuamente seus limites. 
5. GIOIA, D. A., CHITTIPEDDI, K. Sensemaking and sensegiving in strategic change initiation. Strategic Management Journal, Chichester, v. 12, n. 6, p. 43348, Sept. 1991. Os autores propőem ainda uma definição alternativa, mais voltada para 0 aspecto estratégico: "Mudança estratégica envolve o esforço de alteração dos modos vigentes de cognição e ação para possibilitarà organização tirar vantagens de oportunidades ou superar desafios ambientais".

6. HERZOG, J. P. People, the critical factor in managing change. Journal of Systems Management, Cleveland, v. 42, n. 3 , p. 6-11, Mar. 1991.

7. Subentende um modelo de escolha estratégica e inclui os processos planejados de mudança. A idéia de cultura organizacional como prática normativa e as correntes do desenvolvimento organizacional e a abordagem sociotécnica também compōem esse grupo. A idéia fundamental é a crença na autodeterminaçāo, na possibilidade de os líderes interpretarem a realidade e determinarem cursos estratégicos de ação.

8. Inclui a corrente da abordagem sistêmica e o conceito de ciclo de vida organizacional, entre outros. A idéia fundamenta é a do conflito sistêmico, da organização como sistema social dentro de outros sistemas sociais, onde coexistem múltiplas relações caracterizadas por interferências e tensões. zacional: "Mudando andei costume, terra e estado, por ver se mudava a sorte dura".

Mais próximos do universo organizacional, Gioia e Chittipeddi utilizam a seguinte definição: "Mudança envolve o esforço de alteração das formas vigentes de pensar e agir dos membros da organização" ${ }^{\prime 5}$.

Para análise desse caso, será adotada uma definição mais ampla: "Mudança organizacional é qualquer transformação de natureza estrutural, estratégica, cultural, tecnológica, humana ou de qualquer outro componente, capaz de gerar impacto em partes ou no conjunto da organização". Portanto, uma mudança pode ser:

- quanto à natureza: relacionada a qualquer característica da organização como organograma, funções, tarefas (mudanças estruturais); mercadosalvo, foco (mudanças estratégicas); valores, estilo de liderança (mudanças culturais); processos, métodos de produção (mudanças tecnológicas) e pessoas, políticas de seleção e formação (mudanças relacionadas a recursos humanos);

- quanto à relação da organização com o ambiente: uma resposta a mudanças nele ocorridas (mudança reativa) ou uma antecipação baseada em expectativas ( mudança voluntária);

- quanto à forma de implementação: reeducativa, coercitiva ou racional.

O tema da mudança organizacional ganhou proeminência devido ao aumento da velocidade das macromudanças e à elevação da taxa de mudanças descontínuas em relação às mudanças evolutivas e incrementais. A conseqüência óbvia de tudo isso foi o aumento do grau de preocupação e atenção das organizações para com esses processos.

Herzog ${ }^{6}$ classifica as situações capazes de provocar mudanças em três categorias, cada uma delas com três possibilidades. Elas podem ter origem tanto na própria organização quanto no ambiente. São as seguintes:

- crises e problemas: dificuldades com a estrutura organizacional; incapacidade de atender às necessidades dos clientes; restrição de recursos;

- novas oportunidades: introdução de novas tecnologias; introdução de novos produtos e serviços; disponibilidade de novos recursos;

- novas diretrizes internas ou externas: adequação a novas leis; adaptação a novas estratégias corporativas; implementação de novos sistemas de controle.

O autor cita uma pesquisa realizada pela Coopers \& Lybrand sobre os objetivos mais frequientes das mudanças. São eles: melhorar a qualidade, aumentar a produtividade, refletir os valores dos novos líderes, reduzir custos e administrar conflitos. Não raro, como no presente case, todos esses objetivos, ou necessidades, aparecem juntos, interagindo entre si.

Finalmente, constatou-se, também através da pesquisa, que a mudança de qualquer elemento da cultura organizacional é uma das mais difíceis de se conseguir.

\section{Contextualismo versus voluntarismo}

Uma classificação possível para as várias correntes de estudo de mudança organizacional pode ser obtida através das abordagens voluntaris$\operatorname{tas}^{7}$ ou contextualistas ${ }^{8}$. Os resultados da análise de um evento real decorrem da abordagem e do ponto de vista adotados. Ocorre que a postura dos pesquisadores é usualmente monotônica: ou assume-se um ponto de vista voluntarista ou adota-se uma abordagem contextualista. Porém, as abordagens contextualistas podem explicar somente alguns fenômenos organizacionais, pois admitem pressupostos não garantidos pelo comportamento humano. Teorias voluntaristas, por outro lado, têm foco essencialmente no comportamento, e ignoram o ambiente. Colocando-se como mutuamente excludentes, essas abordagens não superam os paradigmas de fronteira. Mas uma mudança organizacional será melhor compreendida se for estudada com as duas lentes. 
Na prática, mudanças voluntaristas e reativas ocorrem de forma simultânea, entrelaçada e indissociável. Embora, em certos momentos, possa-se afirmar que ocorre uma mudança planejada - voluntarista - , suas causas e raizes têm sempre elementos externos - contextuais. Inversamente, embora se possa dizer, em alguns momentos, que ocorre uma mudança adaptativa, provocada por eventos externos, sempre haverá fatores internos relacionados. A realidade será sempre caracterizada por múltiplos fluxos interagindo de forma complexa, como poderemos verificar na apreciaçāo do case.

\section{Cultura e mudança planejada de cultura}

Até meados da década de 70, falar em mudança organizacional correspondia predominantemente a falar em projeto ou (re)desenho organizacional. A idéia de mudança estava centrada no conceito de alteração de organograma, na criação, modificação ou extinção de cargos e funções. Falar em mudança e, principalmente, praticar mudança, significava primordialmente mudar estruturas.

Embora o trabalho de Elliot Jacques, na Glacier Metal $^{9}$, nas décadas de 40 e 50, já mencione o conceito de cultura, é somente nos anos 80 que essa abordagem vai ganhar corpo e fama ${ }^{10}$. Grande parte do interesse pelo tema se deve ao fato de muitos administradores começarem a perceber que, após operar todo tipo de mudança em suas empresas, não tinham feito o suficiente, ainda era necessário mudar os valores comuns e as crenças dos grupos para que os resultados positivos surgissem.

Para Schein ${ }^{11}$, o conceito de cultura é estruturalmente complexo e envolve um grande conjunto de pressupostos e crenças, que defínem como os membros de um grupo vêem suas relações internas e externas. Tendo esse grupo uma história compartilhada, esses pressupostos, alinhados entre si, gerarão paradigmas comportamentais de alta ordem sobre a natureza do espaço, realidade, tempo, pessoas e relações.

Segundo o autor, o conceito de cultura pode ser melhor compreendido se decomposto em três níveis: o nível dos artefatos visíveis, o nível dos valores que governam o comportamento das pessoas e o nível dos pressupostos inconscientes ${ }^{12}$. A cultura, para Schein, afeta todos os aspectos da organização: estrutura, estratégia, processos e sistemas de controle.

A apropriação do conceito de cultura por consultores e teóricos organizacionais é permeada por ambigüidades, paradoxos e polêmicas ${ }^{13}$. Uma delas é a discussão sobre a possibilidade ou não de mudar a cultura de uma organização. Muitos defensores dessa idéia advogam não só que é possível mudar uma cultura, mas que isso pode ser feito de forma planejada ${ }^{14}$. Mas mesmo entre eles, existe consenso de que não se trata de uma tarefa fácil.

A literatura gerencialista tem sido pródiga em divulgar casos de sucesso envolvendo mudança cultural e não se pode negar que muitas organizações têm tido eficácia nesse tipo de autotransformação. Mas dois fatos não devem ser esquecidos: primeiro, que a divulgação da mudança é em si uma peça de afirmação do próprio processo, apoiando sua legitimação; segundo, que a maioria desses processos é representativa da superação do modelo de administração taylorista-fordista, envolvida num movimento maior de macromudanças. Assim, um processo de mudança cultural planejada poderia ser melhor denominado de interiorização e agilização de macrotendências ambientais.

Para Sathe ${ }^{15}$, uma mudança profunda somente ocorre quando as pessoas percebem que seus pressupostos não são mais validados pela realidade. $O$ processo é normalmente doloroso e pode incluir doses não homeopáticas de ansiedade, culpa e perda da autoconfiança.

Pessoas que não aceitam novos padrões devem ser removidas para evitar racionalizações inapropriadas sobre o processo. Existe nesse procedimento um duplo efeito positivo: primeiro, uma limpeza ideológica ${ }^{16}$; segundo, a inibição natural, entre os que ficam, em exibir as mesmas racionalizações inapropriadas. Todo esse processo, segundo Sathe, ajudaria a constituir o comprometimento necessário para a mudança.
9. JACQUES, E. Intervention and changement dans l'entreprise. Paris: Dunod, 1972, 300 p. A edição original, inglesa, é do início da década de 50 e narra um caso de intervenção cultural e social numa empresa industrial, operada por uma equipe do Instituto Tavistock.

10. Ver CULTURING Change. The Economist, London, v. 316, $\mathrm{n}$. 7662, p. 65, July 7, 1990 e DUMAINE, B. Creating a new company culture. Fortune, New York, v. 121 , n. 2 , p. $55-8$, Jan. 15 , 1990.

11. SCHEIN, E. H. Organizational culture and leadership. San Francisco: Jossey-Bass, 1988, $358 \mathrm{p}$.

12. Os dois primeiros representam os valores manifestos de cultura, enquanto o nível dos pressupostos inconscientes seria a própria cultura. Hofstede observa uma divisão análoga à de Schein, em valores e práticas. As práticas sāo manifestações da cultura, traduzidas em símbolos, heróis e rituais, enquanto a essência da cultura é formada por valores, no sentido de sentimentos amplos e gerais sobre bom $e$ ruim, belo e feio, normal e anormal, racional e irracional, sentimentos que geralmente são inconscientes e que não podem ser observados, mas estão manifestos em comportamentos. Ver HOFSTEDE et al., Measuring organizational cultures: a qualitative and quantitative study across twenty cases. Administrative Science Quarterly, v. 35, jun. 90. Thévenet desenvolve o conceito de Schein, afirmando que a cultura é um processo contínuo de aprendizagem, em contraposição a alguma coisa que possa ser mudada ou criada. Ver THÉVENET, Maurice. A cultura de empresa hoje em dia. Revista de Administração da USP, v. 26, n. 2, abr./jun. 91.

13. Fitzgerald, por exemplo, condena essa apropriação. Para ele, enquanto consultores e acadêmicos de linha gerencialista passam a usar a cultura como prática para melhorar organizaçōes, os etnologistas, em cujo campo o conceito surgiu, já superaram o método e a tradição colonialista associada à forma prática de análise na qual o conceito encontrou traduç̧̃o. Ver FITZGERALD, T. H. Can change in organizational culture really be managed? Organizational dynamics, New York, v. 17 , p. 4-15, autumm 1988. 
14. Kilmann, entre outros, propõe uma metodologia estruturada para mudança de cultura. Ver KILMANN, R. H. Gerenciando sem recorrera soluçōes paliativas: um programa totalmente integrado para criar e mantero sucesso organizacional. Rio de Janeiro: Qualitymark 1991,256 p. Outro autor que segue essa linha é Thévenet. Ver THÉVENET, M. Cultura de empresa: auditoria e mudança. Lisboa: Monitor, 1990.

15. Apud FREITAS, M. E. Cultura organizacional: grandes temas em debate. São Paulo: FGV/EAESP, 1989, 213 p. (dissertacão de mestrado). Ver capítulo 8-Mudança cultural, no qual a autora mostra as várias correntes de pensamento sobre a operacionalização de mudanças culturais nas organizações.

16. Alguns autores, mesmo não identificados com a linha do humanismo-radical, têm condenado essa postura. 0 argumento é que a pluralidade de culturas seria aceitável $\mathrm{e}$ até útil. Com um monoteísmo cultural, a organizacão criaria um círculo de autoreferência e excessiva auto-estima dificil de romper, inibindo críticas necessárias a quebras de paradigmas e avanços.

17. Essa atitude transformadora tem seus limites definidos pelos interesses corporativos, validados pela leitura da realidade de mercado e dos imperativos do sistema concorrencial.

18. DEAL, T. E., KENNEDY, A. A. Corporate culture: the rites and rituals of corporate life. New York: Addison-Wesley Publishing Company Inc., 1988, $232 \mathrm{p}$.

19. KANTER, R. M. The change masters. New York: Touchstone Book, 1984, 432 p.

20. Want propōe um "gerenciamento do ciclo de mudança". 0 autor criou um modelo que relaciona o estágio de vida da organização com os tipos de mudança possivivis e suas características. WANT, J. M. Managing change in a turbulent business climate. Management Review, New York, v. 79, n. 11, p. 3841, Nov. 1990.
Um complemento institucional necessário é a mudança do sistema normativo, através de novos padrões implícitos ou explícitos de recompensa e punição. Nas organizações neotayloristas, a lealdade e o comprometimento aos novos valores devem ser constantemente reafirmados e atualizados. Nesse contexto, os funcionários passam de reprodutores passivos da cultura a agentes ativos de transformação ${ }^{17}$ de valores.

Deal e Kennedy ${ }^{18}$ acreditam que mudar tornou-se a tal ponto um modo de vida para as organizações que elas não mudam mais para adequar-se ao ambiente, mas simplesmente porque se espera que elas mudem. Os autores consideram que, em geral, subestima-se o tempo necessário para operar mudanças organizacionais por não se levar em conta os laços das pessoas com os elementos culturais - heróis, lendas, valores, rituais cotidianos etc. Ao mesmo tempo em que se constitui num componente agindo a favor da inércia, a cultura protege a organização dos modismos e flutuações de curto termo.

Os autores acreditam que a mudança é necessária quando ocorrem grandes perturbações ambientais e mudar torna-se uma questão de sobrevivência. Os fatores de sucesso necessários à mudança seriam os seguintes: reconhecimento da importância de se ter consenso sobre a necessidade de mudança; comunicação clara dos objetivos e das alterações a serem implementadas; esforço especial no treinamento; dar tempo ao tempo e encorajar a idéia de mudança como fator de adequação ao meio.

Embora admitam que cultura organizacional ainda seja uma caixa-preta, Deal e Kennedy acreditam que intervenções de sucesso possam ser realizadas, desde que haja sensibilidade suficiente para com os atributos-chave culturais.

Kanter ${ }^{19}$ considera que as mudanças culturais devem se basear nos pontos fortes e tradições da empresa. Para a autora, não há alquimia possível, apenas um enorme esforço para direcionar algumas inovações que sejam adequadas ao estágio de vida e momento da orga-

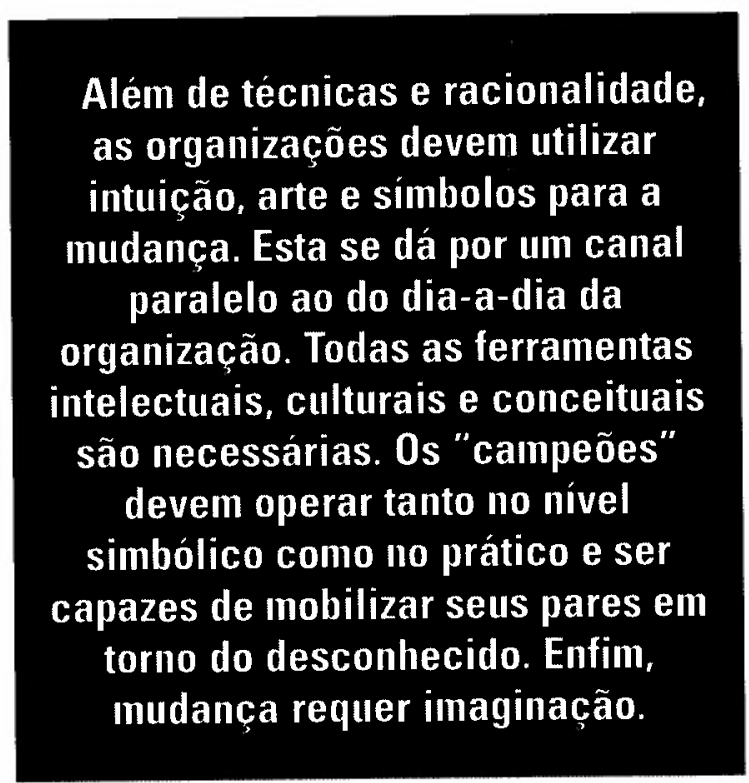
nização ${ }^{20}$. Dessa forma, a arquitetura da mudança requer uma profunda avaliação do passado da empresa e a verificação da existência de relações de confiança e cooperação que suportem o processo. É preciso desvendar a superfície dos fatos e reescrever a história oficial do grupo.

Para Kanter, os grandes elementos da mudança são os seguintes: usar a tradição como ponto de partida; criar ou utilizar eventos catalisadores; tomar decisões e cursos estratégicos de ação e utilizar "campeões" como veículos de ação para a mudança.

Além de técnicas e racionalidade, as organizações devem utilizar intuição, arte e símbolos para a mudança. Esta se dá por um canal paralelo ao do dia-a-dia da organização. Todas as ferramentas intelectuais, culturais e conceituais são necessárias. Os "campeões" devem operar tanto no nível simbólico como no prático e ser capazes de mobilizar seus pares em torno do desconhecido. Enfim, mudança requer imaginação.

\section{Paradigmas como filtros: a dificuldade em mudar}

Em grande parte do tempo, as mudanças ocorrem de forma incremental nas organizações. Decisões de alterações são tomadas sucessivamente, em decorrência de eventos externos e internos. Esse modelo decisório é adequado à necessidade de perenidade e harmonia dos membros das organizações; eles intermediam, através de modelos interpretativos, suas 
relações com a complexidade ambiental. A evolução incremental é gerenciada consciente e racionalmente pelos líderes, como forma de lidar com as incertezas do ambiente.

Segundo Johnson ${ }^{21}$, evidências empíricas demonstram que as decisões gerenciais referentes às mudanças são tomadas dentro de um contexto político-social, tendo a experiência gerencial como filtro de estímulos internos e externos. O ambiente, por si só, não provoca mudanças dentro da organização. São as pessoas que criam novos rumos e cursos estratégicos e os criam, através de paradigmas ${ }^{22}$.

Mudanças ambientais nem sempre são percebidas pela organização. $\mathrm{O}$ contrário também pode ocorrer: a organização superestimar uma mudança ambiental e originar uma mudança interna. Para Johnson, o gerenciamento estratégico pode ser visto como uma resposta da organização, ao longo do tempo, a um ambiente de negócios que é, em essência, internamente construído. Como a ação gerencial é mediada por paradigmas, dificuldades podem surgir quando as mudanças ambientais não estão alinhadas com os padrões culturais, sociais e políticos da organização. Em outras palavras, mudanças ambientais radicais podem exigir mudanças nos valores mais profundos da organização, de forma que o velho paradigma dê origem a um novo, capaz de dotar a organização de novos padrões interpretativos e nova capacidade de resposta.

Mas isso não é o que normalmente ocorre. Os líderes geralmente não gostam de lidar com a ambigüidade e o desconhecido. Assim, tentarão lidar com situações, por vezes inteiramente novas, procurando usar um instrumental antigo e conhecido. A conseqüência prática é que a posição da organização vai se tornando cada vez menos alinhada com o meio ambiente, resultando numa afetação da performance. Quando o desvio é notado, a organização entra num período de flutuação, uma busca de soluções conhecidas para problemas nem sempre conhecidos, o que resulta em falta de direção clara. Finalmente, ocorre a quebra de paradigma e uma mudança radical tem lugar.

Nesta seção, a história recente da Rhodia Farma será reconstituída a partir dos depoimentos coletados nas entrevistas. Para enriquecer a narrativa, os depoimentos foram inseridos no texto ${ }^{23}$.

\section{A corporação}

A Rhodia S.A., subsidiária do grupo francês Rhône-Poulenc, tem sua história no Brasil marcada por seu primeiro produto: o folclórico lança-perfumes, importado no início do século e fabricado até a década de 60, quando foi proibido pelo presidente Jânio Quadros.

Hoje, a empresa é o primeiro grupo privado do setor químico no Brasil, com um faturamento anual próximo do patamar de um bithão de dólares. Suas atividades abrangem cinco setores: fibras e polimeros, agroquímica, especialidades químicas, intermediários orgânicos e minerais e saúde - que inclui a Rhodia Farma. A empreșa está organizada na forma matricial e em unidades de negócio (S.B.U.'s).

Após sucessivos programas de reestruturação, o quadro de funcionários caiu de cerca de 14.000 (em 1989) para cerca de 9.000 (em 1993). Essa redução foi obtida através de um redimensionamento estratégico - com a venda de alguns negócios -, programas de terceirização e planos de demissão voluntária e orientada.

\section{O Prhoex}

A compreensão dos eventos posteriores ao chamado colapso industrial de 1991 na Rhodia Farma só é possível se considerarmos a forte influência do Prhoex - Processo Rhodia de Excelência - sobre
21. JOHNSON, G. Managing strategic change - strategy, culture and action. Great Britain: Long Range Planning, v. 25 n. 1, p. 28-36, 1992.

22. Paradigmas, nesse sentido são mecanismos cognitivos, um conjunto de pressupostos e crenças intimamente ligados à realidade organizacional e normalmente aceitos, que moldam a visão da organizaçāo sobre suas relações internas e com o ambiente. Pode-se dizer, dessa forma que paradigmas atuam como filtros da realidade.

23. Foram entrevistadas as seguintes pessoas: Paulella, diretor geral; Barella, diretor industrial; Tosta, gerente de relações industriais; Darienzo, gerente de produçāo; Donaldo, farmacêutico responsável; Daniel, gerente de qualidade farmacếutica; Edwin Gilmar e Kerginaldo, chefes de departamento/área; Delma, Reny e Nivaldo, supervisores; e Arnóbio, Borgo, Ricardo e Almir, operadores. 
24. Extremamente significativa, mas năo surpreendente, pois já se constitui um padrão em muitas organizações, é o conflito explícito ou implícito - com a área de Recursos Humanos. Visto por alguns autores como simples disputa de território e zona de influência, esse conflito significa uma importante barreira ao avanço dos processos de transformação. Para uma discussão mais aprofundada do tema ver STOREY, J. Developments in the management of human resources. London: Blackwell, 1992.

25. Cultura e liderança: incluem a criaçāo de instrumentos de recursos humanos compatíveis com us novos conceitos de trabalho, prätica de um novo estilo de liderança - participativo - e mudança cultural - que poderia ser de forma simples definida pelo abandono do modelo tradicional taylorista-fordista em favor da adoção de práticas próximas da flexibilidade criativa dos japoneses e suecos. Grande foco è dado ao :rabalho participativo, à comunicação e transparência, ao rompimento de barreiras estruturais e à valorizacãa dos grupos. Conceitos: inclui a formação conceitual dos funcionários e utiliza como ferramenta a divulgação de casos de sucesso. Novas formas de trabalhar abrange o sistema de planejamento integrado, os sistemas de medição, o uso de ferramentas estatísticas e metodologias estruturadas para tomada de decisão, a reorganização do trabaIho, o sistema de qualidade assegurada e as ações junto aos clientes.

26. Não se trata aqui do conceito de qualidade mais amplo, como vem sendo adotado desde a década de 80 - com os conceitos de TQM, por exemplo - , mas de um grande rigor com o controle do produto final, característico de uma abordagem que marcou o movimento da qualidade no seu princípio, na década de 40 , e que é hoje considerado conceitualmente superado. a corporação. O processo teve seu início em 1986 e foi, desde pelo menos 1990 , fortemente influenciado pela abordagem da cultura organizacional.

Irradiado a partir de uma área corporativa central, que conta com cerca de dez funcionários, o processo se propaga pela organização através de uma rede formal de coordenadores e multiplicadores e por uma rede informal crescente de simpatizantes e praticantes. É intcressante notar a penetraçāo heterogênea do processo: hoje coexistem na empresa desde áreas que o adotam e praticam - como a Rhodia Farma - até setores ou grupos que ainda estão na fase de assimilaçāo e adoção do discurso ${ }^{24}$.

Um importante pressuposto do Prhoex é a crença na capacidade de operação de processos planejados de mudança e na possibilidade de intervenção cultural. Embora seja possível detectar uma herança da abordagem sociotécnica e do desenvolvimento organizacional, a maior influência conceitual do processo advém da produção gerencialista americana, das idéias ligadas ao movimento da qualidade total e da visão sistêmica da organização. Também são importantes alguns autores ligados à metáfora da cultura organizacional, como Edgar Schein, Terence Deal, Alan Kennedy e Ralph Kilmann.

Opcracionalmente, o processo

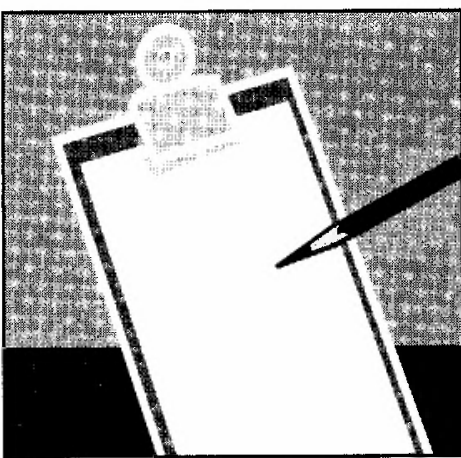
busca realizar seus objetivos "aumento da satisfação dos clientes" e "recuperação da rentabilidade" - através de uma espiral movimentada por três vetores: cultura e liderança, conceitos e novas formas de trabalhar ${ }^{25}$.

Em termos gerais, o Prhoex pretende ser um instrumento de modernização do estilo gerencial, buscando continuamente idéias e conceitos e traduzindo-os em práticas no interior da empresa.

\section{O setor farmacêutico no Brasil}

A indústria farmacêutica no Brasil caracteriza-se por uma forte concorrência e um mercado pulverizado. O setor sofre alto grau de regulamentação -- por parte do governo e seus órgãos de controle , devido à própria natureza da atividade. Segundo o gerente industrial Barella: "Nós não produzimos um produto, nós produzimos um bem social". Essa característica soma-se a uma outra, que é a obsessão pela qualidade, tomada no sentido restrito do termo ${ }^{26}$.

Além disso, no Brasil, o setor sofreu, durante muito tempo, controle rigoroso de preços, o que afetou fortemente sua rentabilidade.

Outra característica da indústria é a participação percentual relativamente pequena dos custos industriais no custo total. Um reflexo disso é um nível menor - em comparação com outros negócios de controle sobre custos de produção. Enquanto em outras indústrias a atenção aos aspectos produção e engenharia de processo é fundamental, na indústria farmacêutica os pontos essenciais são a Pesquisa e Desenvolvimento, o Marketing e Vendas.

O setor é altamente centrado em si mesmo, havendo pouca interação com outras indústrias. Isso ocorria na Rhodia Farma, apesar de sua existência no seio de uma corporação com atividades têxteis e químicas, com as quais poderia trocar experiências gerenciais, administrativas ou mesmo tecnológicas.

Os processos de fabricação são caracterizados por ciclos longos, produção essencialmente em batchs - o que a aproxima de operações seriadas - , grande diversidade de produtos e baixa flexibilida- 
de operacional, motivada pela necessidade de controle e pela característica física das unidades, com compartimentos isolados.

\section{A Rhodia Farma - unidade Santo Amaro}

A atividade farmacêutica da Rhodia no Brasil data da década de 30, quando foi implantada uma linha de produção na fábrica de Santo André.

A unidade estudada, em Santo Amaro, é hoje um dos dois locais de produção farmacêutica da empresa ${ }^{27}$. Originalmente, a unidade pertencia à Upjohn, tendo sido incorporada em 1986, num processo de absorção iniciado naquele ano e completado em 1990.

Seu volume de produção é de cerca de 50 milhões de unidades / ano e inclui as principais fórmulas galênicas clássicas: comprimidos, cápsulas, drágeas, injetáveis, liofilizados e líquidos. São 40 produtos e 114 diferentes apresentações. Aempresa ocupa hoje o décimo lugar no ranking do setor, com um faturamento bruto que se aproxima de $130 \mathrm{mi}^{-}$ thões de dólares e uma participação de mercado ao redor de $3 \%$.

Oefetivo é de cerca de 600 pessoas, a maior parte alocada na divisão industrial -340 pessoas. O quadro técnico é considerado de bom nível e experiente. As instalações são de porte - escala - internacional e a tecnologia é considerada razoável.

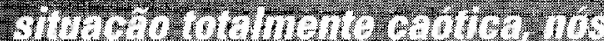

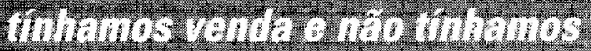

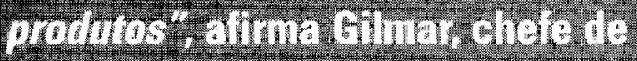

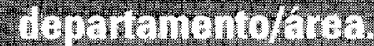

Antecedentes: da fusão industrial ao colapso de 1991

No quadro de adequaçăo estratégica operado na Rhodia, na década de 80, decidiu-se pela compra da unidade da Upjohn. O projeto previa a fusão administrativa e industrial, com a transferência das linhas de produção da unidade Santo André para Santo Amaro. Esperava-se, com isso, gerar ganhos de escala e sinergia. Entretanto, a operacionalização do projeto revelou-se mais complicada que o previsto. A partir dos depoimentos, tanto de funcionários vindos de Santo André como de Santo Amaro, pode-se ter uma idéia clara dos problemas enfrentados nessa difícil transição.

"Depois da fusão: fusão e confusão ... Houve a necessidade de fazer uma concentração industrial, trazer a nossa fábrica de Santo André para cá, todos os funcionários, equipamentos ... complicado ... chegamos a uma situação totalmente caótica, nós tínhamos venda e não tinhamos produtos", afirma Gilmar, chefe de departamento/área.

Segundo o farmacêutico responsável Donald, "teve uma fase que foi um turbilhão, houve muita troca de chefias, a estrutura mudava praticamente todo mês."

Significativamente, todos os depoimentos coletados definiram o problema maior como um choque de culturas: a cultura Rhodia (francesa) versus a cultura Upjohn (americana). "Não houve respeito por essa diferença de culturas, nem de uma parte, nem de outra", declara Daniel, gerente de qualidade farmacêutica.

As diferentes práticas tecnológicas e estilos gerenciais provocaram o surgimento de uma série de conflitos interpessoais e intergrupais, conforme o depoimento do gerente de Relações Industriais Tosta: "(Os anos de 90 e 91) foram muito dramáticos aqui na Rhodia... Vários fatores levaram a uma desagregação empresarial, uma desestruturação, principalmente em nível tecnológico, em nível de indüstria ... Chegou
27. Existe uma pequena unidade na fábrica do Cabo, em Pernambuco, cuja produçāo deverá ser assimilada por Santo Amaro em 1994. 
28. Plano de demissão voluntária, incluindo um "pacote" de benefícios.

29. Na Rhodia, os gerentes, chefes e supervisores são comumente chamados de líderes. um momento em que as pessoas não tinham o controle do processo, e nem mais o conhecimento do processo de produção. Por outro lado, era unia época dificil para a Rhodia como um todo, uma época que a Rhodia estava passando pelos grandes questionamentos estruturais, e nós não deixávamos de passar por isso também."

No primeiro momento da fusão, muitas pessoas deixaram a cmpresa, tanto da Rhodia quanto da Upjohn, principalmente após o "Plano Rhodia"28. Os métodos de trabalho eram diferentes nas duas fábricas, assim como a tecnologia. Com o alto turnover e treinamento insuficiente, a mão-de-obra restante não estava qualificada para operar os equipamentos.

Muitos entrevistados mencionaram que a administração de pessoal era "terrorista", de "chicote", e "não havia comprometinento" com os empregados. O líder" era "ausente" e "só repreendia". "Outro problema grave aqui era o dos salários... As pessons eram tratadas como gado. Deu uma baixa no mercado, mandavam 30 embora. Subiu um pouco, contratavam mais 30 . Por quê? O trabalho não era especializado, e o individuo se sentia assim tambem, aqui era sempre algo temporário ... A segmentação das funções faz com que o trabalho seja pouco nobre", complementa Barella.

A organização da empresa era considerada "caótica", uma "confusĩo". Devido à estrutura extremamente compartimentada, havia metas divergentes e grande dispersão de esforços. "O controle de qualidade era controle de qualidade; manutenção, manutenção; ninguém ajudava ninguém ... O 'departamentalismo' era muito grande", afirma Edwin, chefe de departamento/área.

Numa tentativa de contornar as dificuldades, a Rhodia chegou a contratar uma empresa de consultoria. $O$ foco de trabalho, porém, foi o estabelecimento de normas e procedimentos, com ênfase no controle. A ação da equipe de consultores foi vista de forma bem crítica pelos entrevistados. Segundo o atual gerente de produção Darienzo: "... eles fizeram um trabalho péssimo. É uma consultoria que não tem conceitos modernos de gerenciamento, de administração. São tayloristas. Eles vêm aqui $e$ acham que uma prancheta, um cronômetro e um chicote fazem a produção sair, e bem feito... Tinham relatórios a que não tínhamos acesso ... Passavam na fábrica não para ajudar o pessoal a melhorar, mas para captar onde estavam as coisas para entregar à diretoria, para queimar as pessoas."

Nesse cenário, a crise relacionada ao recall não chegou a ser surpreendente, pois foi, segundo Barelli, "o ponto culminante de um processo de desestruturação ... Tudo isso causava uma pressão muito forte ... Tudo isso (gerava) círculos viciosos: o sujeito ganha pouco porque trabalha mal, trabalha mal porque ganha pouco. O sujeito não pára a máquina porque não produz, não produz porque a máquina quebra ... Perdia-se dinheiro; o produ to que você vendia era mais barato que o custo da produção."

Em. 1991, a crise se agravou com o aumento dos pedidos de produção não atendidos (subordens), o nível de estoque altíssimo, prejuízos e conflitos, tanto na divisão industrial como entre esta e outras áreas. Todo esse processo gerou vários incidentes, culminando com o recall.

\section{Um marco na crise: o recall de produto}

Em outubro de 1991, uma farmácia do Rio de Janeiro descobriu uma caixa de medicamentos com problemas: a embalagem de um medicamento continha cartuchos de outro. Recebida a informação, os controles de estoque e expedição não foram suficientes para, de imediato, permitir a identificação da fonte do problema ou mesmo sua extensão. A direção da empresa optou, então, pelo recall, amplamente divulgado através da imprensa e meios de comunicação e com sérias implicações em termos de imagem da empresa perante os clientes, órgãos do governo, classe médica e mesmo público interno. 
Uma investigação posterior constatou que, no total, 18 cartuchos haviam sido trocados.

Apesar da consciência de que problemas estruturais já existissem. antes do recall, o evento sinalizou a gravidade da situação. Nesse momento, a corporação já havia iniciado mudanças profundas nas lideranças da Rhodia Farma. Foi nomeado um interventor, pessoa de confiança da direção da empresa, que permaneceu na divisão industrial de novembro de 1991 a março de 1992. Também houve substituições na equipe gerencial - gerente geral, gerente industrial e gerente de produção.

O diretor geral Paulella comenta que "no primeiro momento tinha o aspecto de mudança total. Nós tivemos um periodo transitório, com una intervenção ... Demorou alouns meses até o próprio pessoal dizer (ao interventor) você tem que ir embora, a gente (o grupo) têm que trabalhar junto."

Foi unânime entre os entrevistados a importância dada à vinda dessas pessoas - mais alinhadas com as novas práticas gerenciais defendidas pelo Prhoex - para o sucesso do processo de mudança. "As pessoas que vieram, vieram com filosofia totalmente oposta daquilo que se tinha anteriormente, filosofia de trabalho, principalmente. Muito mais participação. A anterior não deixava que as pessoas participassem, não aceitavam as colaborações ... era aquela chefia que ameaça", declara Donaldo.

A recuperação, após o período da intervenção, pode ser dividida em duas fases: a primeira, de março de 1992 até o início de 1993, caracterizada por forte recuperaçāo da performance; a segunda, iniciada em 1993 e caracterizada pela implementação da metodologia de planejamento integrado, que busca um novo salto na performance.

\section{A primeira fase de recuperação: quebrando o ciclo vicioso}

A primeira fase de recuperação foi marcada pela definição de objetivos estratégicos simples e claros. Fles foram divulgados para a divisão industrial em reuniões com todas as lideranças: garantir a qualidade dos produtos; recuperar a credibilidade junto aos clientes internos e externos; participar da recuperação da rentabilidade da empresa através da redução de custos operacionais, melhoria da qualidade, melhoria da segurança, aumento da produtividade e terminar com o "achismo".

A reestruturação da divisão industrial envolveu esforços para resolver os problemas que haviam levado à situação de crise. $O$ início do trabalho foi assim definido pelos novos líderes: "A primeira coisa foi montar uma equipe ... então começa o trabalho de reconstrução ... Tínhamos objetivos. Primeiro, acabar com o "achismo", através de estudos aprofundados... Recuperar a credibilidade ... a meta foi eliminar subordens ... era eficácia com eficiência minima ... vamos fazer produto, transformar o círculo vicioso em círculo virtuoso ... restabelecer a organização ... Criamos uma gestão industrial, uma área de custos, uma área de desenvolvimento de qualidade... Primeiro você cria uma cultura Rhodia Farma. Vamos pegar o que é bom da Rhodia e o que é bom da Upjohn. Vamos fazer uma mistura disso", declara Barella.

"A departamentalização na área da Farma era assustadora... Não existiam reuniões para discutir ... cada departamento tinha os seus objetivos ... isso era grave ... O nosso trabalho era tentar organizar, tentar quebrar a departamentalizaçäo ... tentar discutir os problemas com todos", complementa Darienzo.

Essa fase caracteriza-se por uma reorganização geral. A estrutura muda e o novo desenho organizacional vai possibilitar maior fluidez na comunicação e na tomada de decisões. Novos departamentos são criados e a equipe de consultoria externa é afastada. Como parte da estratégia de mudanças, um nível hierárquico é eliminado: o último nível de supervisão. Com isso, ocorre uma redefinição de responsabilidades nas áreas operacionais. De outro lado, em função do objetivo de integração no ambiente de trabalho e redução de conflitos, um certo número de funcionários é afastado. 


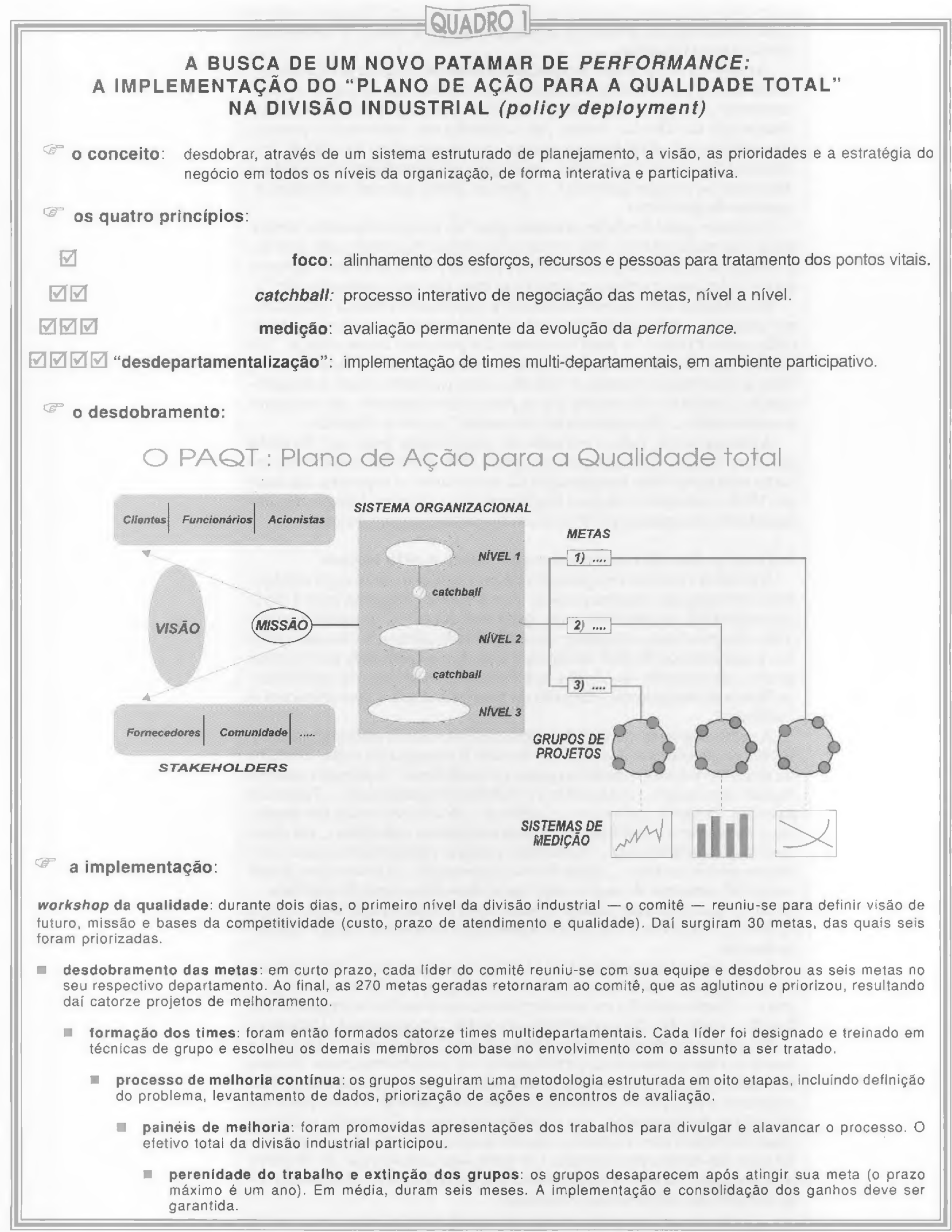


No geral, bons resultados foram alcançados. O nível de subordens caiu significativamente e os conflitos internos diminuíram, como confirma Tosta: "O relacionamento interno melhorou sensivelmente ... com isso (também) a forte departamentalização que havia até o início de 92."

Porém, tomou-se consciência de que os custos não estavam melhorando e que muitos problemas estavam sendo tratados de forma imprópria. Diagnosticou-se a necessidade de implementação de um programa de qualidade, dando especial ênfase para a disseminação de uma visão sistêmica da organização.

\section{A segunda fase de recuperação: mudança planejada}

A segunda fase caracteriza-se por uma mudança estratégica. Um dos eventos mais importantes nessa fase foi o "Workshop da Qualida$\mathrm{de}^{\prime \prime}$, que envolveu o primeiro nível hierárquico da divisão industrial. "O workshop foi um grande caminho para alcançar as metas... A forma como foifeito enriqueceu o trabalho", afirma Gilmar.

O objetivo principal era conseguir consenso e comprometimento em torno de um plano de ação para 1993. Esse plano foi denominado PAQT (Plano de Ação para a Qualidade Total - ver quadro 1) e definido como o "plano operacional de implantação do Prhoex em Santo Amaro". Envolveu a aplicação de várias ferramentas, metodologias e sistemas, como o planejamento integrado, os times de projetos multifuncionais, o autocontrole do ciclo de produção (apoiado por kanban), o treinamento de pessoal, o desenvolvimento de fornecedores etc.

Barella conta que "o PAQT foi uma segunda fase ... Gerenciar crise é totalmente diferente de gerenciar melhoria continua ... O PAQT vai ser em março de 93 ... Entre maio e setembro (de 92) uma série de coisas foram feitas, melhoramos o nivel das pessoas, trocamos gente, contratamos gente de fora ... Aí você muda a ferramenta ... muda o estilo de gerenciamento."

Há, nessa fase, uma grande ênfase em treinamento e na adequação do perfil das pessoas à nova estratégia, como afirma Edwin: "O que melhorou foi o treinamento. O que temos de horas de treinamento é fora de série."

O chefe de departamento Kerginaldo reforça essa opiniáo: "Nós implantamos um programa muito forte de treinamento, de conscientização de $G M P^{30}$, de segurança também ... foi muito bom o indice que atingimos com relaçāo ao treinamento."

"Eu tinha $80 \%$ do efetivo com primeiro grau incompleto... Fizemos uma escola interna para o pessoal", complementa Barella.

Conseguiu-se uma melhora efetiva do ambiente de trabalho, com ampla participação e troca de idéias. Segundo o gerente de Relações Industriais Tosta: "Existe hoje uma forte credibilidade nesse relacionamento. É um relacionamento líder-liderado muito transparente em todos os niveis

30. Good Manufacturing Practices, ou Boas Práticas de Manufatura: conjunto de normas que garante, teoricamente, condições adequadas de segurança, higiene e qualidade nas indústrias farmacêuticas. 
... Hoje as pessoas discutem pelos corredores ... sem receio de que uma punição vai ocorrer por isso."

A supervisão deixou de ser cerrada. Foram organizados grupos de trabalho para melhoria da qualidade e processo (ver quadros 2 e 3 ) e começaram a surgir equipes de trabalho semi-autônomas (ver quadro 4).

Segundo o supervisor Nivaldo, "numa troca de $240 \mathrm{ml}$ para $80 \mathrm{ml}$, na mesma linha, demoravam-se oito horas. Hoje, demoram-se três. Antes era um só que trocava, hoje é a equipe inteira. É uma mudança de cultura intensa."

"Sempre imperou o trabalho individual, não o trabalho de equipe, e aqui a filosofia é o trabalho de

A linha de produção de injetáveis só podia mudar de produto duas vezes por semana, mas a fabricação de lotes grandes era incompatível com as flutuaçóes de demanda e gerava problemas de atendimento dos pedidos.

O grupo, formado por representantes da produção, manutenção, controle de qualidade e armazém, trabalhou por cinco meses para reduzir o tempo de preparação - set-up - das máquinas.

Com ajuda de um diagrama de Pareto, foram descobertos os pontos essenciais a serem atacados. Após uma série de ensaios e modificações, conseguiu-se atingir um tempo de set-up três vezes menor que o original.

No meio do trabalho, o grupo deparou-se com um desafio: "Discutimos a idéia con o grupo e só seria viável se tioéssemos um conjunto novo de enchimento ... um mecânico dé ama idéia excelente ... nós fabricáoamos um produto que usava um forramental que estava encostado, ... ele sabia pela sua experiéncia que se você regulasse a máquina poderia compensar a diferença de ferramental ... fizemos um teste que dell certo", declara o chefe de departamento/área Kerginaldo.

Os ganhos, seguidos de um treinamento realizado com operadores $\mathrm{e}$ mecânicos, permitiu que as duas trocas por semana fossem transformadas em duas trocas por dia, aumentando significativamente a flexibilidade da linha e eliminando os problemas de modulação da produção. equipe ... O trabalhador contente e integrado produz melhor ... A nova filosofia tem que ser você ter um aliado atrás de cada equipamento. O operador tem muito poder atrás de uma máquina ... ele tem esse poder e ninguém tira dele. Näo adianta chicote na mäo que não vai resolver o problema. O administrador está sentado na cadeira dele e ele não tem muito controle sobre isso", afirma o supervisor Reny.

Além das mudanças no ambiente de trabalho, várias mudanças no cotidiano do empregado ocorreram, muitas em resposta às suas próprias demandas como modificaçöes nos serviços de transporte e alimentação, atendimento dentário no local de trabalho e melhoria do sistema de comunicação.

\section{Perspectivas}

Apesar da divisão industrial ter claramente revertido a situação de crise que atravessava, a empresa como um todo ainda deve enfrentar alguns problemas e desafios no futuro próximo

Como uma preparação para 94 foi realizado, no final de $1993, \mathrm{um}$ "II Workshop da Qualidade", envolvendo um número maior de funcionários que o anterior. $O$ foco desse workshop foi a consolidação e expansão da implementação em toda a divisão industrial de células autogerenciadas, além de uma segunda fase de implantaçăo de projetos de melhoramento.

Nessa terceira fase, portanto, passa a ser prioritária a busca da evolução do modelo de organização do trabalho, como meio de dotar a organização de maior flexibilidade e capacidade de resposta às mudanças ambientais.

\section{Síntese comentada}

No ambiente turbulento das organizaçōes contemporâneas, os movimentos de mudança não podem ser analisados sob a ótica da causalidade simples e do determinismo cartesiano. Eles exigem um olhar complexo, compativel com o emaranhado de relaçōes culturais, de poder, formais e informais existentes nesses sistemas. 


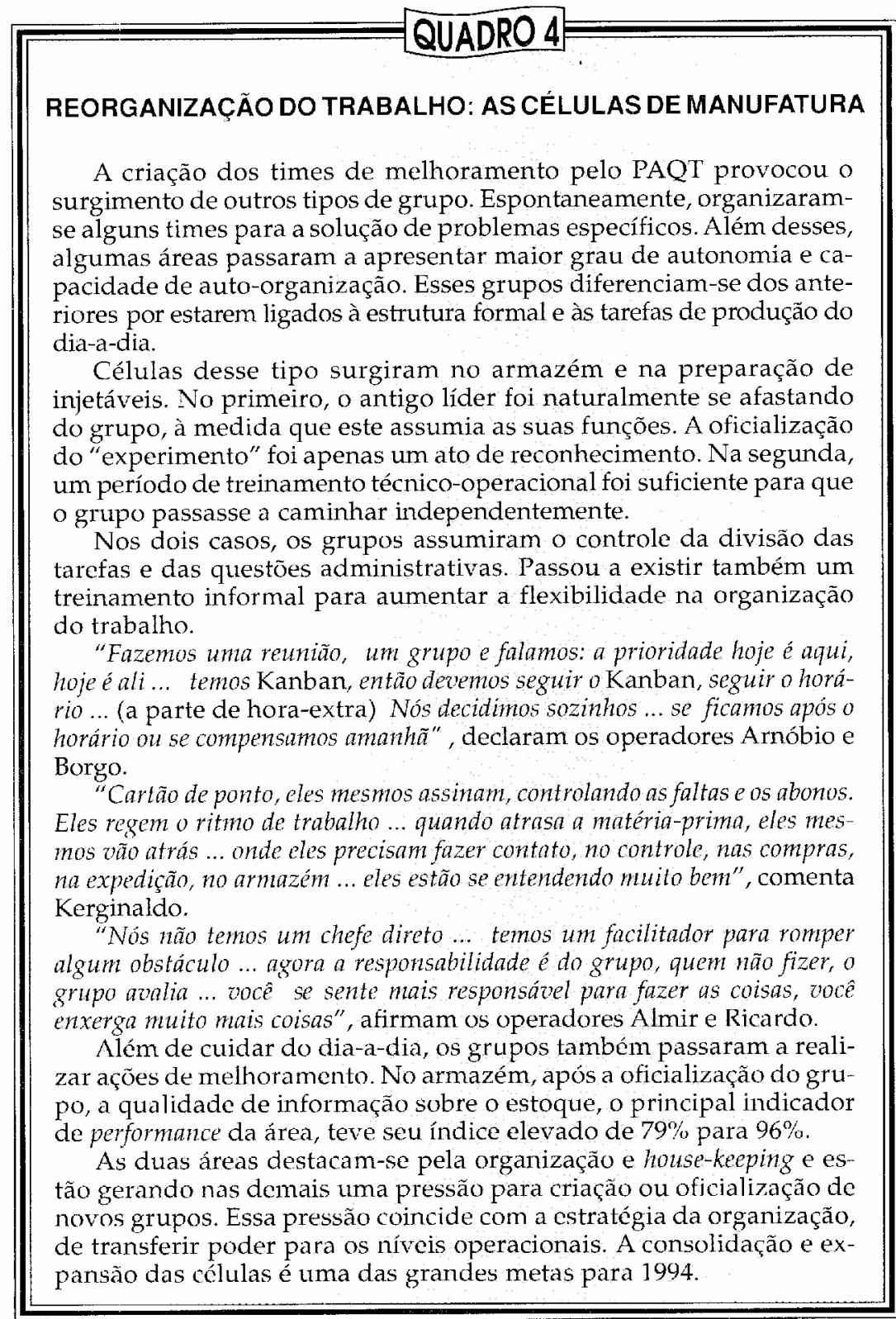

Começaremos analisando o contexto gerador do colapso ind ustrial de 1991. Um primeiro ponto que chama a atenção são as disfunções originadas no processo de concentração industrial das linhas de produção de Santo André e Santo Amaro. Além da dificuldade de juntar operacionalmente diferentes tecnologias, linhas de produto e procedimentos, surge aqui a difícil tarefa de juntar pessoas e grupos de diferentes origens. Nesse aspecto, a abordagem cultural é útil para mostrar como indivíduos, com passado profissional diferente e formas distintas de conduta, podem se chocar num novo ambiente de trabalho, se não houver preparação prévia para o processo de mudança. Nesse sentido, foram significativos alguns depoimentos sobre segregaçăo, envolvendo tanto operários quanto líderes. Além de considerações financeiras e estratégicas, o sucesso a longo termo de aquisições como essa depende da correta administração do processo de combinação de diferentes práticas, estilos gerenciais e cultura $\mathrm{s}^{3 i}$.

Outro ponto importante relaciona-se à característica da própria indústria farmacêutica. Inserida num contexto marcado pela necessidade de controles, cla os reproduz e amplia internamente no sistema produtivo, na
31. Fusões, aquisições e alianças estratégicas tornaram-se extremamente populares nos últimos anos, especialmente pela possibilidade de realização rápida dos planos estratégicos. Infelizmente, a cultura é tradicionalmente foco de pouca atenção nesses processos e, até que um novo equilíbrio seja atingido, muito tempo passa e muita troca de pessoal costuma ocorrer Períodos de três a cinco anos são normais para que um processo dessa natureza se complete. Ver WALTER, G. A. Culture collisions in mergers and aquisitions in FROST et al. Organizationa/ culture. Newbury Park Sage, $1985,419 p$. Ver também MALEKZADEH, A.R. NAHAVANDI, A. Making mergers work by managing cultures. The Journal of Business Strategy, May/June 1990, p. 55-7. Os autores propõem uma caracterizaçāo de quatro diferentes tipos de combinação cultural, indo da total absorção à completa separação. São elas: desculturação, assimilaçāo, integraçāo e separação. 
32. A estratégia de ação de uma organização é raramente não-controversa. Ela aglutina muitos pontos de vista e interesses diferentes. 0 desacordo é raramente analítico; ele reflete em geral interesses conflitantes. Ver HUFF, A. S. Arhetorical examination of strategic change in PONDY L et al Organizational Symbolism. Greenwich: Jai Press, 1983, $307 \mathrm{p}$.

Na empresa estudada, parecem especialmente difíceis as decisões envolvendo troca de pessoas, em particular no nivel gerencial. Essa característica pode ser ligada a três fatores: primeiro, à estrutura matricial, de poder difuso e processo decisório lento; segundo, a existência de redes informais de poder $e$, terceiro, a um traço cultural ligado à preservação dos quadros gerenciais, mesmo em épocas de crise. forma de conservadorismo administrativo e apego a normas e regulamentos. É essa inflexibilidade que, somada às dificuldades da concentração industrial e ao choque cultural, fechou o ciclo vicioso que levou ao colapso.

Agindo para, involuntariamente, dar coesão a esse ciclo, existe sobre a organização uma pressão por resultados, exercida num momento delicado de transição. É importante ressaltar que esse momento é caracterizado por uma indefinição quanto à própria identidade da organização, quesito básico para que as pessoas se situem e consigam direcionar esforços para objetivos predefinidos. Há de se considerar que essa pressão estava interiorizada em cada membro, dada a consciência da incapacidade de atingir as metas de produção. Esse vetor de pressão atua sobre o ciclo vicioso formado que, como uma bola de neve, gera uma degradação das relações e da própria performance organizacional, culminando com o evento do recall de produto.

Esse evento deve ser visto como um marco, como resultante de um processo maior, no qual os atores organizacionais, embora procurando acertar, não conseguem superar o ciclo sistêmico que leva ao colapso. Os demais componentes da crise, como a saída de funcionários experientes e o excesso de horas-extra, devem também ser vistos como resultantes do ciclo.

A conjuntura crítica e, principalmente, os incidentes que antecedem o recall, conseguem disparar na organização o gatilho da mudança, transformando em ação a consciência da necessidade de intervenção. Essa consciência já vinha se formando, mas não conseguia por si só romper as barreiras da inércia que antecedem alterações traumáticas ${ }^{32}$. Assim, pode-se afirmar que os mesmos fatores que precipitaram a crise também agiram como catalisadores das mudanças. Em outras palavras, foi necessário uma crise profunda - ou pelo menos o consenso grupal de que existia uma para provocar um processo de reversão.

Então, à tomada de decisão segue-se um período de intervenção que poderíamos chamar de ambíguo. Por um lado, chegam à organização consultores e interventores destinados a "pôr ordem na casa" e que agem com ortodoxia, reforçando controles e normas. Nesse processo, algumas evoluções conseguidas, em termos de disciplina industrial, são acompanhadas por um acirramento do ciclo vicioso. Por outro lado, são trazidos novos líderes, sintonizados com um novo estilo gerencial, mais aberto e participativo. Se, por algum tempo, essas duas correntes intervencionistas coexistem, revelando uma certa dubiedade da própria corporação, é a segunda corrente que vai prevalecer sendo, sem dúvida, responsável pela quebra do ciclo vicioso e pela reversão das tendências que levavam ao colapso.

Embora, de início, a ação desses líderes seja no sentido de apenas identificar os problemas principais e tratá-los com soluções conhecidas, sua conduta e a forma de implementação das medidas já são suficientes para sinalizar um novo rumo para o sistema organizacional. Pode-se afirmar que o essencial dessa etapa é a sinalização da intenção de mudança de curso e a determinação de diretrizes simples, comunicadas a todas as lideranças.

Na prática, o rompimento do ciclo ocorre pelo enfraquecimento parcial das pressões por performance, filtradas pelas novas lideranças, e a definição de prioridade de esforços sobre alguns gargalos da produção. Uma vez revertida a situação - e percebida esta reversão - , a carga negativa acumulada pelo grupo transforma-se em carga positiva, capaz de fazer o sistema saltar da degradação para a evolução e mantê-lo em curso por um bom tempo.

Assim, a superação da crise e a retomada da capacidade produtiva, dentro de parâmetros adequados de segurança e qualidade, ocorrem de forma natural, no sentido que o próprio grupo tende a corrigir-se, a partir de uma sinalização inicial de rumo e caminho. Não se pode, é claro, minimizar o sem-número de decisões e ações que foram tomadas para manter o curso da recuperação.

O observado parece validar a hipótese de um processo de alteração de traços culturais - marcadamente estilo gerencial - catalisado por novos 
Na sociedade contemporânea, as organizações devem interpretar

continuamente 0 ambiente, originando movimentos internos de mudança.

0 ponto-chave é a passagem de uma postura passiva ou meramente reativa para uma postura pró-ativa. Essa passagem implica a constante manipulação, por parte dos líderes, de símbolos, valores e linguagem.

Dentro da organização, ocorre uma socialização contínua dos funcionários, para internar os novos significados e controlar comportamentos e performances.

Na prática, essa passagem também significa a substituição do controle coercitivo pelo controle via cultura organizacional. líderes, mas essencialmente calcado num movimento maior de macromudanças. Daí a sensação de naturalidade, mesmo numa estrutura conservadora como a de uma unidade farmacêutica, quando se supera alguns padrões próximos da ortodoxia taylorista-fordista em favor do neofuncionalismo da administração participativa.

Então, à medida que o processo se desenvolveu - durante 1992 - , percebeuse que o novo estilo gerencial foi se afirmando através de um novo discur-so e prática, estabelecendo forte vínculo entre os novos líderes e seus liderados ${ }^{33}$.

Chama também a atenção como, na organização pós-recall, rituais, símbolos e discurso ganham novo status. O dia-a-dia passa a ser marcado por reuniões de grupo, apresentações sobre trabalhos realizados e mecanismos informais e subjetivos de recompensa. Ao mesmo tempo, a história do próprio processo é racionalizada, transforma-se em discurso oficial e espalha-se por todos os níveis da organização ${ }^{34}$. E, como em toda "tragédia", nesta também surgem heróis, geralmente na figura de alguns novos líderes ${ }^{35}$.

Todo esse aparato ajuda a legitimar e reforçar a própria mudança, construindo uma rede de comprometimento, lealdade e confiança. É significativo nos depoimentos a dificuldade das pessoas em criticar o processo embora não haja nenhum cerceamento visível -, a alusão aos heróis do processo e a presença de frases feitas sobre "choque de culturas" $\mathrm{e}$ "mudança cultural".

O período que se segue, de implementação do PAQT - Plano de Ação para a Qualidade Total - , representa a necessidade de dar consistência estrutural para o processo de mudança, num momento em que a crise estava superada e o rumo da mudança suficientemente amadurecido. Devese também destacar sua função de artefato cultural, de afirmação do novo estilo gerencial. O PAQT passa, então, a estruturar de forma mais efetiva os fluxos de esforços, alinhando-os com os objetivos organizacionais maiores.

É interessante observar o timing dos líderes da organização, sentindo que já era momento de realizar um salto qualitativo pouco tempo após a superação da crise. ${ }^{36}$

Fechando a síntese da narrativa, pode-se afirmar que a trajetória seguida pela organização levou ao atendimento dos objetivos do negócio através da prática de um novo estilo gerencial e implementação de novas metodologias de planejamento. Ficam também claros os resultados conseguidos em termos de redução de conflitos, comprometimento, lealdade e grau de participação. É nítido o orgulho do próprio trabalho e a noção "somos especiais e estamos fazendo algo novo". O uso de símbolos, discurso e rituais é, sem dúvida, o grande responsável por essa coesão e uniformização de visões e sensações.

Um aspecto que não poderia deixar de ser comentado é que a concentração industrial, embora tenha sido, pela condição em que foi conduzida, um gerador da crise, foi, sob o ponto de vista estratégico, estrutural e cultural, um fator positivo para a performance. A unificação das atividades num único local e o aumento da independência do negócio em relação à corporação tendem a ter reflexos positivos sobre os processos decisórios, $\mathrm{o}$ fluxo de informação e a própria afirmação da identidade do sistema.

Finalmente, cabe discutir alguns desafios e dificuldades com os quais a organização deve se deparar num futuro próximo:
33. Ver GIOIA, D. A., CHITTIPEDDI, K. Op. cit. Os autores utilizam os conceitos de sensemaking - que opera no sentido dos niveis mais baixos para os mais altos na hierarquia - e sensegiving - que opera no sentido oposto - para mostrar a construção de uma nova rede de significados num processo de mudanca a partír da acão da liderança. As sucessivas interaçōes entre liderança e grupos de liderados constróem o novo ambiente cultural, reforçando os lacos de confiança e comprometimento.

34. Martin e Powers constataram empiricamente a relação entre histórias e comprometimento organizacional. Comparada a dados estatísticos objetivos 0 impacto de sagas e mitos é muito maior. Ver MARTIN, L., POWERS, M. Truth or corporate propaganda: the value of a good war story in PONDY et al. Op. cit.

35. Os administradores conduzem a organização, os heróis a criam e recriam, vencendo desafios e revertendo situacōes difíceis. Eles tornam as grandes conquistas plausíveis e a o alcance humano, fornecem modelos de comportamento e modificam e preservam os valores centrais da organizacão, personificandoos. Ver FREITAS, M. E. Op. cit. p. $59-61$.

36. Van der Erve utiliza o conceito de curva "S" para analisar a evolucão das organizacōes. Para 0 autor, existe um momento adequado para o salto de uma curva para outra. Se a persistência, além do tempo correto, pode levar à estagnação, saltos excessivos podem gerar turbulências e inviabilizar o sistema. VAN DER ERVE, M. The power of tomorrow's management. Management Decision, Yorkshire, v. 28, n. 7, p. 55-63, 1990. 
37. É interessante notar a existência de grupos de cultura forte, preservando essa cultura mesmo quando dentro de organizações. É normalmente o caso de profissionais especializados, como os médicos. Sua impermeabilidade a mudanças vem da sua rede própria de relações $\theta$ significados

38. Será utilizada na análise a abordagem das organizações como sistemas de controle social. Ver MOTTA, F. C. P., Vasconcelos, I. F. F. G. e Wood Jr., $T$. Controle social nas organizacões. Revista de Administração de Empresas-RAE, v. $33, \mathrm{n}$. 5; p. 68-87, São Paulo, set./out. 1993.
- o locus da mudança. O processo todo envolveu mais profundamente a divisão industrial, embora outras áreas tenham passado por grandes transformaçōes. O espírito de corpo desenvolvido nessa divisão pode ser um obstáculo à integração com as demais áreas. Num sentido inverso, o contágio cultural pode ocorrer a partir da história de sucesso. Resta administrar esse novo choque de culturas;

- a mudança em áreas de fronteira. Embora não seja um sistema fechado, a divisão industrial, em comparação com outras áreas, é mais isolada do meio ambiente. $O$ desafio é desenvolver formas alternativas de operacionalização de mudanças em áreas intensamente mergulhadas no meio ambiente, como equipes de vendas e outros grupos similares ${ }^{37}$;

- a questão da recompensa. Numa fase posterior deve haver aumento de pressão por vantagens em termos de salários e benefícios por parte dos operários. Embora tenha-se notado inibição no tratamento dessa questão e exista forte consciência de uma situação de mercado que desfavorece o operário farmacêutico, pode-se esperar pressões em função dos aumentos de produtividade conseguidos e do aumento de capacidades e responsabilidades. Num outro grau, essa pressão deve atingir escalões superiores, que tendem a ter maior consciência do trabalho realizado e do seu diferencial por tê-lo realizado;

- a contradição aumento de produtividade versus efetivo. Com a introdução de novas tecnologias e métodos, tende-se para uma redução gradativa do efetivo. Essa possibilidade, por sua vez, pode levar a uma queda no comprometimento dos operários com os processos de melhoria. É claro que a transparência e as formas de demissão podem reduzir o impacto negativo. Por outro lado, corre-se o risco de instalar na organização um clima de competitividade individual com uma luta pela manutenção de emprego e/ou ascensão - mesmo num ambiente de valorização dos grupos;

- a vontade de melhorar. Deve ocorrer uma pressão até certo ponto positiva por uma melhora das condições de trabalho e novas oportunidades, nem sempre compatíveis com as baixas taxas de crescimento da indústria e da empresa;

- a ameaça permanente do meio ambiente. Não são poucos os casos de projetos organizacionais interessantes que foram total ou parcialmente desativados por problemas ligados à performance global da organização. Em muitos casos isso se deveu à concentração de energias em setores não-essenciais para a estratégia do negócio. Daí a necessidade de consolidar as conquistas - especificamente a ligação "novo modelo gerencial" com a melhora da performance - diante dos centros de poder da corporação e, ao mesmo tempo, cuidar dos outros aspectos essenciais do negócio.

A superação do modelo de organização do trabalho: uma questão aberta Sem dúvida, do ponto da continuidade do processo de mudança, o maior desafio da organização será a evolução do modelo de organização do trabalho, com a implementação dos grupos autogerenciados. Nesse ponto do trabalho, é importante realizar uma discussão teórica sobre um dos aspectos mais essenciais do case: o esgotamento e renovação do modelo taylorista-fordista da organização estudada ${ }^{38}$.

As organizações, para responder à demanda do mercado, precisam de confiabilidade e reprodutibilidade. Essas mesmas características impõem normas e procedimentos que constituem barreiras contra a adoção de práticas flexíveis e mudanças. Mesmo as empresas que superaram o binômio produção/consumo de massa vêem-se diante desse paradoxo, ainda que num grau atenuado. Assim, é uma característica intrínseca das organizações burocráticas - o apego às normas e o culto dos regulamentos e do tecnicismo, aliado à superespecialização e à compartimentagem - que dificulta sua adaptação à nova realidade de mercado.

Na sociedade contemporânea, as organizações devem interpretar continuamente o ambiente, originando movimentos internos de mudança. $O$ 
ponto-chave é a passagem de uma postura passiva ou meramente reativa para uma postura pró-ativa. Essa passagem implica a constante manipulação, por parte dos líderes, de símbolos, valores e linguagem. Dentro da organização, ocorre uma socialização contínua dos funcionários, para in ternar os novos significados e controlar comportamentos e performances. $\mathrm{Na}$ prática, essa passagem também significa a substituição do controle coercitivo pelo controle via cultura organizacional.

Pode-se analisar esse pêndulo de transformação através dos conceitos de socialização e individuação ${ }^{39}$. Um ponto fundamental, a ser avaliado, é quando a exacerbação do processo de socialização, com a manipulação de símbolos, pode gerar impacto negativo sobre o individualismo criativo, necessário para a renovação da organização. Não há dúvidas do impacto positivo do relaxamento dos controles coercitivos sobre a performance, mas não se pode ainda avaliar os limites do novo estilo gerencial. ${ }^{40}$

Para Rouanet ${ }^{41}$, em certas condições a psicologia coletiva pode anular a psicologia individual, a inteligência do indivíduo declina, sua afetividade aumenta exageradamente e a linguagem passa a ser instrumento de mobi lização. Nas palavras do autor: "Todas as características da psicologia de massas - o desaparecimento da individualidade, a uniformidade de pensamentos $e$ emoções, o predomínio da afetividade e de conteúdos inconscientes - tudo corresponde a atividades mentais arcaicas, como as que devem ter prevalecido na horda primitiva."

Os autores mais próximos do paradigma humanista radical tendem a criticar a administração participativa a partir de uma preocupação com a emancipação e o desenvolvimento do indivíduo. Involuntariamente, talvez, seus alertas sirvam como indicadores de limite para certas práticas gerenciais emergentes, como procuramos mostrar nos parágrafos precedentes.

Distante desse arcabouço, outros autores também têm se preocupado com a questão da viabilidade dos grupos. Beer, ${ }^{42}$ por exemplo, estuda os sistemas de controle não hierarquizados a partir de uma perspectiva fortemente influenciada pela cibernética e pela teoria dos sistemas.

Para Beer, o grande objetivo é a busca da democracia perfeita, a ausên cia de ascendência. Embora não tenha ainda constituído uma teoria acabada do funcionamento dos grupos, o autor, testando várias configurações e formas de trabalho, chegou a conclusões interessantes acerca dos arranjos mais performantes. Ele desenvolveu o conceito de tensegrity, a partir da idéia do domo geodésico de Buckminster Fuller. Tensegrity - de integridade tensional - significa, em termos de estrutura, equilíbrio através de tensão e não através de compressão. O desafio é criar um grupo autogerenciado que seja simultaneamente criativo, democrático e eficiente.

Os modelos desenvolvidos por Beer são caracterizados por participação voluntária, autonomia, igualdade, cooperação, diversidade e autocrítica. O princípio geral é criar uma organização do trabalho que evite, através de recursos estruturais, os vícios mais comuns dos grupos, que levam ao empobrecimento do processo decisório e a resultados de consenso do tipo "máximo denominador comum."

Apesar de já terem sido utilizados em algumas empresas, os modelos de Beer permanecem como artefatos de laboratório. Isso não impede que alguns conceitos tenham utilização mais ampla. Seu trabalho interessa especialmente às organizações que estão caminhando para o gerenciamento por grupos autônomos, indicando medidas concretas para conseguir maior efetividade nessas implementações.

A organização estudada, pelo caminho que está trilhando, tende a colocar-se muito brevemente diante desses problemas de fronteira, que deverão exigir cada vez maior aprofundamento conceitual e sensibilidade prática dos envolvidos. Pela riqueza da experiência já acumulada e pelas perspectivas de novos avanços deve, sem dúvida, ter seus passos acompanhados.

\section{7}

39. Quando entra em contato com a organização, o indivíduo se confronta com expectativas amblguas: ao mesmo tempo que vê na organização as possibilidades de suprir algumas necessidades, também vế-se obrigado a renunciar a certa margem de liberdade. Ao ser mergulhado na cultura da organização, ele tende a internar seus símbolos. Como os dirigentes e uma certa elite na empresa detêm maior poder na determinação das diretrizes organizacionais, interpretando o sistema maior de inserção da organização no macroambiente, são seus valores que vão permear a cultura organizacional. Socialização pode ser definida como o processo pelo qual um indivíduo com amplas possibilidades desenvolve padrões de comportamento restrito, adequando-se às normas grupais. $E$ a qualidade do processo que val determinar 0 grau de lealdade $e$ comprometimento do indivíduo e, potencialmente, sua produtividade. Individuação é o processo pelo qual o indivíduo procura influenciar a organização, na expectativa de maximizar sua satisfação pessoal. 0 processo de individuacão mais aceito pela organização poderia ser denominado de individualis mo criativo, no qual o funcionário aceita os valores e regras básicas e questiona, ou rejeita, somente o que é periférico.

40. Alguns autores têm sido bastante críticos com as novas práticas gerenciais, apontando-as como taylorismo simbólico, pois mantêm a crença básica no one best way. Por ísso, elas não sobreviveriam muito tempo, pois sofreriam das mesmas contradiços do modelo que tentam superar.

41. ROUANET, S. P. O mal-estar na modernidade. São Paulo: IDE v. 23, p. $40-53,1993$

42. BEER, $S$. Origens of team tensegrity in SPEJO, R., SCHWANINGER, M. Organisational fitness: corporate effectiveness through management cybernetics. Frankfurt: Campus 1993. Ver também no mesmo volume GOMES, P. Organising for autonomy e SHECTER, D. Beer's tensegrity and the chalenge of democratic management.

Os autores gostariam de agradecer à direção da Rhodia Farma, pela colaboração e autorizacão para publicacão do trabalho; aos funcionários que prestaram depoimentos, pelo interesse e disposicão; e ao Eduardo Gusso, da Coordenadoria do Prhoex, pela sugestão e insistência para que este trabalho fosse realizado. 